Int. J. Electrochem. Sci., 12 (2017) $5511-5520$

\title{
Electrochemical Determination of Cu(II) Ions Based on Ag/Pd Alloy for Water Quality Early Warning
}

\author{
Xingpu Qi ${ }^{1,2}$, Jianzhong Qian ${ }^{2}$, Tong Chen ${ }^{1}$, Daoli $\mathrm{Lu}^{1}$ and Bin Chen ${ }^{1, *}$ \\ ${ }^{1}$ Jiangsu University, No.301 Xuefu Rd, Zhenjiang, Jiangsu, 212013, P.R.China \\ ${ }^{2}$ Jiangsu Agri-animal Husbandry Vocational College, No 8 East Phoenix Road, Taizhou , Jiangsu \\ ,225300,P.R.China \\ *E-mail: xingpuqi111@163.com
}

doi: $10.20964 / 2017.06 .49$

Received: 6 March 2017 / Accepted: 29 March 2017 / Published: 12 May 2017

\begin{abstract}
With a chemical and eco-friendly in situ reduction technique, an excellent Ag-Pd bimetallic nanoparticle (Ag-Pd)-based hybrid was successfully synthesized in this study. To determine copper(II) ions in water, this work employed differential pulse adsorptive stripping voltammetry (DPAdSV) and preconcentration methods. Furthermore, the sensor feasibility was studied with river and tap water as real specimens. The results revealed the potential of the proposed electrochemical sensor to be applied for the early testing of water quality based on its desirable behavior in $\mathrm{Cu}$ (II) determination in real specimens.
\end{abstract}

Keywords: Silver; Palladium; Alloy; Water quality; Electrochemical determination; Copper ions

\section{$\underline{\text { FULL TEXT }}$}

(C) 2017 The Authors. Published by ESG (www.electrochemsci.org). This article is an open access article distributed under the terms and conditions of the Creative Commons Attribution license (http://creativecommons.org/licenses/by/4.0/). 